\title{
Gastric Adenocarcinomas in Central Tunisia: Evolution Specificities through Two Decades and Relation with Helicobacter pylori
}

\author{
Mohamed Amine Elghali ${ }^{a} \quad$ Amine Gouader ${ }^{a}$ Rym Bouriga $^{b}$ \\ Mohamed Mahjoub ${ }^{c}$ Mohamed Salah Jarrar ${ }^{a}$ Sonia Ziadid ${ }^{d}$ Moncef Moknid \\ Fahmi Hamila ${ }^{a}$ Rached Ltaeif ${ }^{a}$ \\ ${ }^{\text {a }}$ Department of Digestive Surgery, Farhat Hached University Hospital, Sousse, Tunisia; ${ }^{b}$ Department of \\ Medical Oncology, Farhat Hached University Hospital, Sousse, Tunisia; ${ }^{\mathrm{C} D e p a r t m e n t}$ of Epidemiology and \\ Hospital Hygiene, Farhat Hached University Hospital, Sousse, Tunisia; ${ }^{d}$ Department of Pathology, Farhat \\ Hached University Hospital, Sousse, Tunisia
}

\section{Keywords}

Gastric adenocarcinoma $\cdot$ Signet ring cells $\cdot$ Intestinal histotype - Proximal or distal gastric cancer .

Epidemiological changes · Helicobacter pylori infection · North-African Arabic country

\footnotetext{
Abstract

Introduction: In developed countries, authors have reported variations over time in the seat and histological type of gastric adenocarcinomas, which were explained by Helicobacter pylori infection (HPI) incidence changes. In North-African countries and the Arabic world, epidemiological changes in gastric adenocarcinomas are still unknown. Our study aims to explore and to describe those changes in central Tunisia. Materials and Methods: This is a retrospective observational and descriptive study including 876 cases based on the National Central Tunisian Register of Cancers over a period of 21 years. Two groups were formed and compared (group A: 337
}

\section{KARGER}

(c) 2018 S. Karger AG, Basel

E-Mail karger@karger.com

www.karger.com/ocl patients from 1995 to 2005; group B: 539 patients from 2006 to 2015). Results: $\mathrm{HPI}$ decreased from $32.6 \%$ in group $A$ to $11.2 \%$ in group $B(p<0.05)$. Signet ring cell carcinomas increased in 2 decades from 14\% in group A to $36 \%$ in group $B$ $(p<0.05)$. Proximal cancers were $16.61 \%$ in group $A$ and increased to $19.66 \%$ in group $\mathrm{B}(p=0.3)$. Total gastrectomy rate was $10.4 \%$ in group A versus $23.2 \%$ in group B ( $p<0.05)$. Conclusion: This study has shown a significant increase of signet ring cell carcinomas with a simultaneous decrease in $\mathrm{HPI}$ in the last decade in central Tunisia.

(c) 2018 S. Karger AG, Basel

\section{Introduction}

The epidemiology of gastric cancer is variable throughout the world [1]. It has a low incidence in Tunisia where it represents the second most common digestive cancer after colorectal cancers. 
In several developed countries, the incidence of gastric cancer has fallen over time, and in most Western countries an epidemiological change concerning gastric adenocarcinomas (GA) was recently reported. For instance, many studies described an increase in cases of GA in the gastric proximal seat (cardia and esophagus bottom) with a decrease in the distal seat (fundus, corpus and pylorus), as well as an increase in the incidences of signet ring cell carcinomas and carcinomas of diffuse histotype, with a decrease in the incidence of intestinal GA $[2,3]$.

In 1994, the World Health Organization (WHO) classified Helicobacter pylori infection (HPI) as a group I carcinogen for gastric cancer [4]. Indeed, more than $80 \%$ of GA were and are still likely due to HPI [5]. Epidemiological variations in GA have been majorly explained by a decline in the incidence of HPI. However, environmental modifications, habits, and cultural differences as well as nutritional patterns seemed to interfere.

The question asked by many authors of developed countries was: does this epidemiological change occur in low- and middle-income countries? In North Africa as for the Arabic world, no objective answer could be given to that question when no work comparing old series of GA to recent ones has yet been published. To help solve this issue, we managed to investigate and then to describe the evolutionary trends of GA in central Tunisia according to histological subtype, tumor seat, and HPI.

\section{Patients and Methods}

\section{Patients and Sampling}

Tunisia's health system has adopted, since 1987, three national registers of cancers (in the North, the Center, and the South) in order to list all cancers diagnosed in the Tunisian territory (in public or liberal sectors of healthcare activities). In these cancer registers, for every patient, data collection always starts with a histological diagnosis (histological evidence) and is then completed with data from medical records (symptoms, clinical features, treatment, and follow-up). In Tunisia, as we do not have electronic medical records yet, every patient has as many medical files as the number of medical and/or surgical departments in which he was treated and followed-up, in addition to the liberal medical sector. For every register of cancers, there is a group of medical staff that is employed full time for collecting and saving all the needed and necessary data.

Our study was based on data from The National Central Tunisian Register of Cancers, covering the population of the states of central Tunisia (Sousse, Monastir, Mahdia, Kairouan, Kasserine, Sidibouzid) where currently near 3 million people are living $(2,989,714$ in $2014 ; 2,814,563$ in $2009 ; 2,610,345$ in $2004 ; 2,281,235$ in $1999 ; 1,952,356$ in 1994) according to the Tunisian National Institute of Statistics [6].

\section{Period of the Study}

We collected documented GA in a retrospective period of 21 years ranging from 1995 to 2015 from The National Central Tunisian Register of Cancers.

\section{Data Collection}

A grid of data collection was specially designed for the purposes of the study and was validated by a multidisciplinary committee formed of surgeons, pathologists, oncologists, and epidemiologists. Data collection was performed by the same physician investigator. We adopted these definitions:

- Proximal tumors are developed in the cardia and/or esophagus bottom, distal locations are the fundus, corpus and pylorus.

- The gross appearance of advanced gastric carcinomas was divided into fungating growth, ulcerating growth, combined ulcerating and fungating, and finally, diffusely infiltrating growth which is also referred to as linitis plastica in signet ring cell carcinoma.

- Lauren classification was introduced in 1965 which distinguished between intestinal (type 1) and diffuse (type 2) histotypes [7].

- Comparison between "WHO 2010" and "Lauren 1965" histological classifications clarifies that intestinal type (Lauren 1965) corresponds to three WHO histotypes (papillary, tubular, and mucinous adenocarcinomas), while diffuse type (Lauren 1965) corresponds to signet ring cell carcinoma and other poorly cohesive carcinoma in WHO classification [8].

HPI status is systematically described in histological reports of gastric biopsies or gastrectomies. All the cases belonging to before 2009 were reclassified according to 2009 TNM classification. Incomplete grids of data were not included.

Study Design

First step

Collected cases were divided into two groups (group A and group B), according to the census period of the patients. Group A ( $n=337$ cases) was formed by the cases identified during a period of 11 years from 1995 to 2005 . Group B ( $n=539$ cases) represented cases registered during the more recent following period of 10 years from 2006 to 2015 .

\section{Second Step}

We proceeded to univariate analysis. All collected cases in the total period of 21 years were divided into two groups, in three modalities: (1) according to the tumor seat (group of proximal tumor seat vs. group of distal tumor seat), (2) according to the tumor histological type (with or without signet ring cells), and (3) according to the HPI status.

\section{Statistical Analyses}

Data seizure and analysis were performed using SPSS 20.0 software. Quantitative variables were presented as averages plus or minus their standard deviations. Qualitative variables were presented as percentages. For each estimate, a confidence interval (CI) was calculated according to the standard formula. When the classical formula application conditions were not fulfilled $(n p<5$ or $n$ $(1-\mathrm{p})<5)$, the Wilson procedure with continuity correction was used.

We proceeded to compare the two groups according to the different collected concepts. For that we used the Pearson $\chi^{2}$ test with 
a significance degree of $p<0.05$. When conditions of the classic formula were not fulfilled, we used the $\chi^{2}$ test with the Yates or Fisher exact test for correction [9].

Ethics

The study protocol was approved by the institute's committee on human research. The published research complies with the guidelines for human studies and animal welfare regulations.

\section{Results}

Description of General Features of the Population

Consultation of The National Central Tunisian Register of Cancers for the last 21 years has revealed 932 cases of histologically confirmed gastric cancers, among which 876 cases were GA ( $94 \%$ of total gastric cancers). The evolutionary trend of GA has two opposite directions - before and after the year 2009 (Fig. 1). Indeed, the incidence and incidence rate of GA first increased from 1993 to 2009, but then decreased in the last 5 years (from 2009 to 2014).

Our series was characterized by male predominance (57.8\%) with a gender ratio of 1.37 . The mean age ( \pm standard deviation) - gender confused - was $59.12 \pm 14.85$ years. For instance, the average male age was $59.52 \pm$ 14.35 years, and that of females was $58.56 \pm 15.52$ years. Age extremes were spread between 20 and 92 years.

Chronic atrophic gastritis was the most prevalent precancerous lesion (23.4\%). Antropyloric tumors (a distal seat) were described in $35.84 \%$, while cardia tumors (a proximal seat) were found in $18.49 \%$. Specific features relating to classes of age, precancerous lesions, and tumor seats are detailed in Table 1.

Combined ulcerating and fungating growth was the most frequent aspect (53.58\%). According to Lauren histological classification (1965) and to WHO histological classification (2010), intestinal type (corresponding to the group of papillary, tubular, and mucinous adenocarcinomas) represented $72.79 \%$ of histological types. Total gastrectomy was reported in $41.24 \%$. Nonmetastatic disease was described in $75.68 \%$. The distributions of GA according to macroscopic and histological characteristics, surgery type, and TNM classification are reported in Table 2.

\section{Analytical Results}

Comparison according to Group Periods

Comparison of the two groups $\mathrm{A}$ and $\mathrm{B}$ corresponding to periods 1 and 2 in relation to the general clinical features and to the main tumor concepts revealed that GA

Gastric Adenocarcinoma in Central

Tunisia

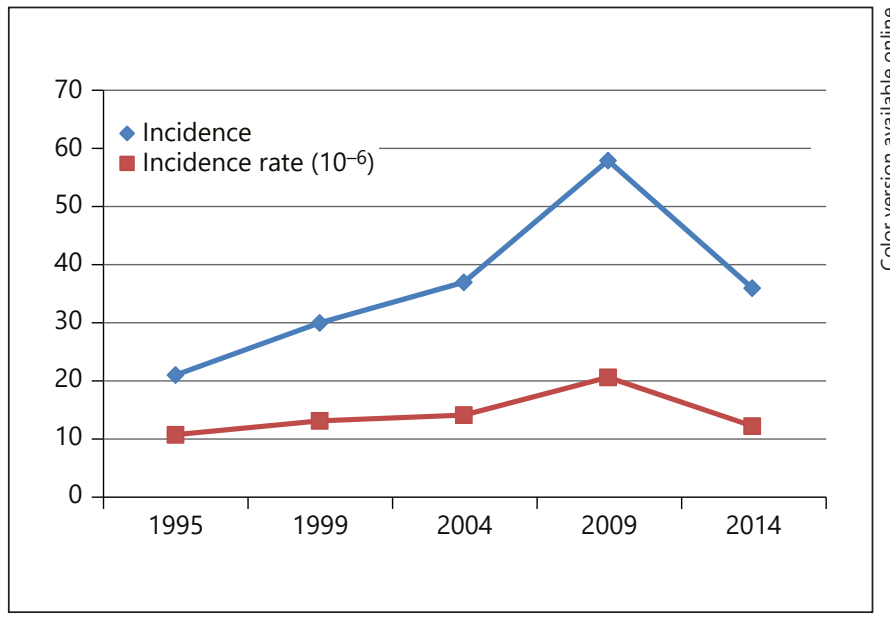

Fig. 1. Evolutionary trend of incidence and incidence rate of gastric adenocarcinomas between 1995 and 2015.

Table 1. Repartition of gastric adenocarcinomas according to age group, precancer lesion type, and tumor seat

\begin{tabular}{lcc}
\hline Studied concepts & $n(\%)$ & $95 \% \mathrm{CI}$ \\
\hline Age group $(n=860)$ & & \\
$<30$ years & $21(2.40)$ & $1.4-3.4$ \\
$30-49$ years & $210(24.40)$ & $21.5-27.3$ \\
$50-70$ years & $404(46.10)$ & $42.8-49.4$ \\
$>70$ years & $225(26.16)$ & $23.2-29.1$ \\
\hline
\end{tabular}

Precancer lesion type $(n=601)$

Intestinal metaplasia $\quad 166(18.9) \quad 15.8-22$

Helicobacter pylori infection $\quad 171(19.5) \quad 16.3-22.7$

Dysplasia

$48(5.5) \quad 3.7-7.3$

Chronic atrophic gastritis $\quad 205(23.4) \quad 20.9-27.7$

$\begin{array}{lll}\text { Hypertrophic gastritis } & 11(1.3) & 0.4-2.2\end{array}$

Tumor seat $(n=876)$

Proximal cardia $(n=162)$

Distal $(n=608)$

Antropyloric

Fundus

Extended

Small curvature

Large curvature

Gastric stump $(n=21)$

Undetermined $(n=85)$

$162(18.49) \quad 15.9-21.1$

$314(35.84) \quad 28.8-44.8$

$128(14.61) \quad 12.3-16.9$

$56(6.39) \quad 4.8-8$

$82(9.36) \quad 7.4-11.3$

$28(3.2) \quad 2-4.4$

$21(2.4) \quad 1.4-3.4$

$85(9.70) \quad 7.7-11.7$

had significantly increased among females ( 37.1 vs. $45.3 \%$; $p=0.017)$ and decreased among males (62.9 vs. $54.7 \%$; $p=0.017)$.

Gastric signet ring cell carcinoma significantly increased in the last 10 years (group B compared to group 
Table 2. Repartition of gastric adenocarcinomas (GA) according to histological type, the performed surgery, and TNM classification

\begin{tabular}{|c|c|c|}
\hline Studied aspects & $n(\%)$ & $95 \%$ CI \\
\hline \multicolumn{3}{|c|}{ Macroscopic aspect of advanced GA $(n=377)$} \\
\hline Ulcerating growth & $76(20.16)$ & $16.1-24.2$ \\
\hline Fungating growth & $86(22.81)$ & $18.6-27$ \\
\hline Infiltrated growth or linitis plastica & $13(3.45)$ & $1.6-5.3$ \\
\hline Combined ulcerating and fungating & $202(53.58)$ & $46.5-60.7$ \\
\hline \multicolumn{3}{|l|}{ Histological type $(n=876)$} \\
\hline Intestinal type & $635(72.79)$ & $68.6-74.6$ \\
\hline Diffuse type ${ }^{\tilde{b}}$ & $241(27.51)$ & $24.9-32.0$ \\
\hline \multicolumn{3}{|l|}{ Resection type $(n=388)$} \\
\hline Total gastrectomy & $160(41.24)$ & $36.3-46.1$ \\
\hline Partial gastrectomy & $219(56.44)$ & $51.5-61.4$ \\
\hline Unresectable tumor & $9(2.32)$ & $0.8-3.8$ \\
\hline \multicolumn{3}{|l|}{ TNM extension } \\
\hline \multicolumn{3}{|l|}{$\mathrm{T}$ (parietal) $(n=376)$} \\
\hline $\mathrm{T} 1$ & $23(6.12)$ & $3.7-8.5$ \\
\hline $\mathrm{T} 2$ & $106(28.19)$ & $23.6-32.7$ \\
\hline T3 & $188(50)$ & $44.9-55.1$ \\
\hline $\mathrm{T} 4$ & $59(15.69)$ & $12-19.4$ \\
\hline \multicolumn{3}{|l|}{$N$ (lymph node involvement) $(n=358)$} \\
\hline No & $128(35.75)$ & $30.8-40.7$ \\
\hline N1 & $149(41.62)$ & $36.5-46.7$ \\
\hline $\mathrm{N} 2$ & $69(19.27)$ & $15.2-23.4$ \\
\hline N3 & $12(3.35)$ & $1.5-5.2$ \\
\hline \multicolumn{3}{|l|}{$M$ (metastasis) $(n=876)$} \\
\hline M0 & $663(75.68)$ & $72.8-78.5$ \\
\hline M1 & $152(17.35)$ & $14.8-19.9$ \\
\hline $\mathrm{Mx}$ & $61(6.96)$ & $5.3-8.6$ \\
\hline
\end{tabular}

Histological type according to Lauren 1965 (and WHO 2010) histological classification. ${ }^{\text {a }}$ Papillary + tubular + mucinous adenocarcinoma. ${ }^{b}$ Signet ring cell carcinoma.

A (14.02 vs. $36.00 \%$, respectively; $p<0.00001)$. We observed a nonsignificant increase in GA of proximal seat. Furthermore, the use of a total gastrectomy significantly increased (23.2 vs. $10.4 \% ; p<0.00001$ ). Documented HPI significantly decreased in patients of group B (32.6 vs. $11.3 \% ; p<0.00001)$, as did chronic atrophic gastritis $(36.2$ vs. $15.4 \% ; p<0.00001$ ) (Table 3 ).

\section{Comparison according to Tumor Seat, Histological}

Type, and HPI Status

The constitution of groups according to some tumor characteristics, and their comparisons with respect to the main studied tumor concepts, is detailed in Table 4. Thus, we have raised that:
- Chronic atrophic gastritis and signet ring cell carcinomas were significantly more prevalent in proximal compared to distal location ( 19.14 vs. $9.70 \% ; p<0.00001$ and 47.43 vs. $26.19 \%$; $p<0.00001$, respectively).

- HPI, chronic atrophic gastritis, and metaplasia were significantly more prevalent in GA of intestinal type rather than that of independent cell (signet ring cell) type ( 24.72 vs. $5.8 \%$; $p<0.00001,29.76$ vs. $6.63 \%$; $p<$ 0.00001 , and 22.99 vs. $8.29 \%$; $p<0.00001$ ).

- Metaplasia, ulcerated macroscopic aspect, and intestinal histotype were significantly more encountered in the presence of HPI (26.9 vs. $17.58 \% ; p=0.048$, 18.7 vs. $7.52 \% ; p=0.044$, and 55.55 vs. $44.05 \%$; $p=$ $0.011)$. 
Table 3. Comparison between the two groups according to patient characteristics, tumor specificities, and surgical treatment

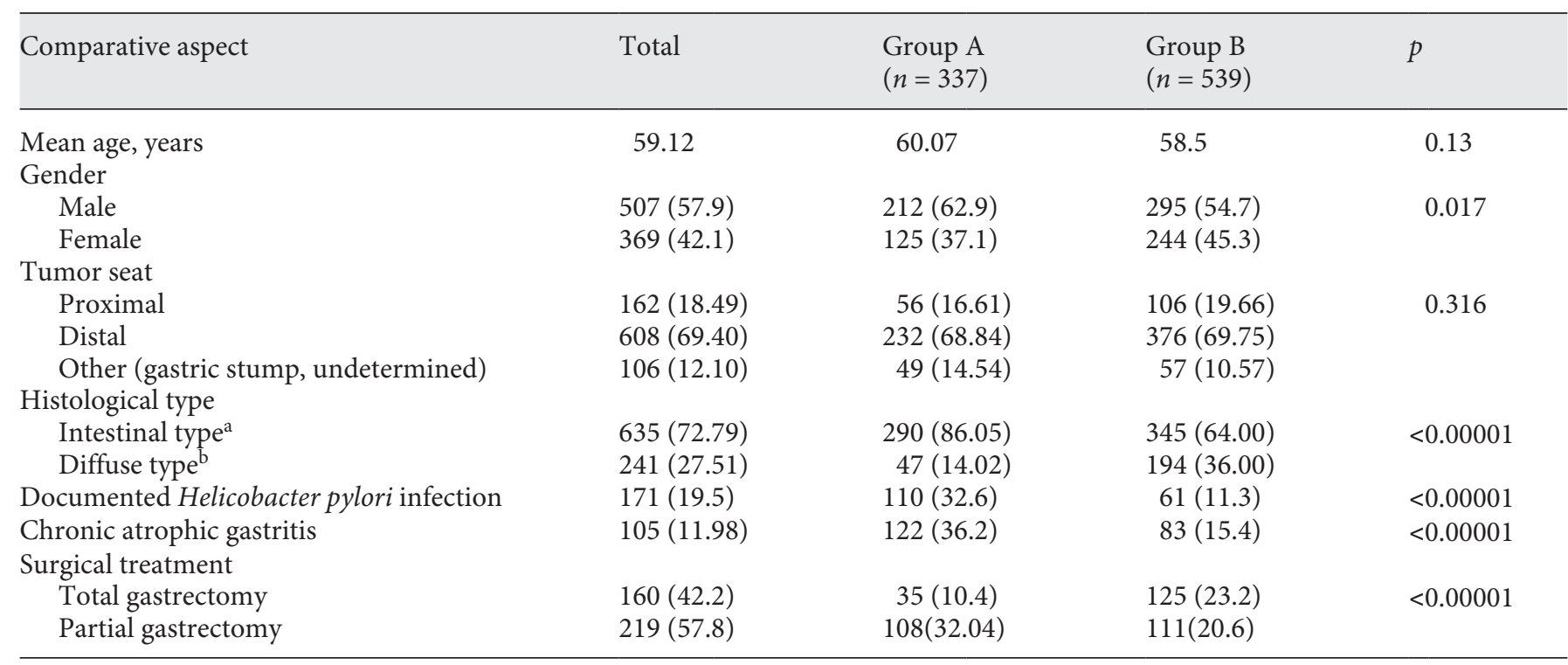

Values are $n$ (\%) unless otherwise indicated. Histological type according to Lauren 1965 (and WHO 2010) histological classification. ${ }^{\text {a }}$ Papillary + tubular + mucinous adenocarcinoma. ${ }^{\mathrm{b}}$ Signet ring cell carcinoma.

\section{Discussion}

In the past 50 years, in many parts of the world, the incidence rates of GA have been declining steadily [10]. Prophylactic measures described in many industrialized countries including use of refrigerated foods, vitamins, minerals, and antioxidants (such as $\alpha$-tocopherol, $\beta$-carotene, vitamin $C$, selenium, curcumin, and green tea), the availability of fresh fruits and vegetables, and a decrease in the use of salt (at the table and for food preservation), as well as the decline in smoking in some industrialized countries, have - as primary prevention contributed to the decrease in the incidence of GA in general. Among the many preventive measures, eradication of HPI was the most effective [11].

Tunisia is a country with a high rate of HPI. In 2010, the result of a HPI serological prevalence study among Tunisian blood donors was 64\% [12]. It was lower than in Peru where it was reported to be $75 \%$ in that same year, and also lower than in South Africa (84.2\%) and the Ivory Coast (80-90\%) [12]. Nevertheless, Tunisia has a low incidence of gastric cancer $(6.6 / 100,000$ inhabitants among males and 3.7/100,000 among females) according to the latest incidence study of 2004 [13]. The exact incidence for central Tunisia was not specified. So despite a very high prevalence of HPI, gastric cancer is rare among South Africans and Southern Indians and has a low inci- dence in Tunisia $[14,15]$. As a matter of fact, the prevalence of HPI and GA rates do not necessarily correlate due to differences in the virulence factors of the bacteria, which confirms the major role of other environmental factors, especially diet, tobacco, and genetic factors [16].

In many countries, eradication of HPI by primary chemopreventive agents including antibiotic treatment and by secondary prevention consisting of endoscopic screening has resulted in a decrease in the incidence of the gastric intestinal histotype [17]. In Tunisia, we do not have a national program of $H$. pylori screening, but as requested by the Tunisian Society of Gastroenterology, all patients addressed for esophagogastroduodenoscopy systematically have biopsies to search for $H$. pylori. They are treated whenever HPI is confirmed. Therefore, we noticed in our series that the prevalence of documented HPI has significantly decreased from $32.6 \%$ in the first decade (group A) to $11.3 \%$ in the second (group B) $(p<0.00001)$.

A preliminary Tunisian study among gastrectomized patients in the Department of General Surgery at Farhat Hached University Hospital, Sousse, has compared epidemiological characteristics of GA between two periods of time, and its results suggested the occurrence of epidemiological changes that could not be significantly proven due to the insufficient number of cases [18]. Those results promoted carrying out our present wider study. Besides, there are many differences between the Tunisian envi- 
Table 4. Comparison of tumor characteristics related to the seat, histological type, and Helicobacter pylori infection

\begin{tabular}{|c|c|c|c|}
\hline \multirow[t]{3}{*}{ Studied concepts } & \multicolumn{3}{|c|}{ Tumoral characteristics } \\
\hline & \multicolumn{2}{|l|}{ Seat } & \multirow[t]{2}{*}{$p$} \\
\hline & proximal $(n=162)$ & distal $(n=608)$ & \\
\hline H. pylori infection $(n=146)$ & $25(15.43)$ & $121(19.24)$ & 0.26 \\
\hline Chronic atrophic gastritis $(n=92)$ & $31(19.14)$ & $61(9.70)$ & $<0.00001$ \\
\hline \multirow[t]{3}{*}{ Signet ring cells carcinoma $(n=241)$} & $77(47.43)$ & $164(26.19)$ & $<0.00001$ \\
\hline & \multicolumn{2}{|l|}{ Histological type } & \multirow[t]{2}{*}{$p$} \\
\hline & $\begin{array}{l}\text { signet ring cells } \\
(n=241)\end{array}$ & $\begin{array}{l}\text { other than signet ring cells } \\
(n=635)\end{array}$ & \\
\hline H. pylori infection $(n=171)$ & $14(5.8)$ & $157(24.72)$ & $<0.00001$ \\
\hline Chronic atrophic gastritis $(n=205)$ & $16(6.63)$ & $189(29.76)$ & $<0.00001$ \\
\hline Metaplasia $(n=166)$ & $20(8.29)$ & $146(22.99)$ & $<0.00001$ \\
\hline \multicolumn{4}{|l|}{ Age groups $(n=876)$} \\
\hline$<30$ years & $7(2.90)$ & $14(2.20)$ & \multirow[t]{4}{*}{$<0.00001$} \\
\hline between $30-49$ years & 77 (31.95) & $133(20.94)$ & \\
\hline between $50-70$ years & $116(48.13)$ & $288(45.35)$ & \\
\hline$>70$ years & $37(15.35)$ & $188(29.60)$ & \\
\hline \multicolumn{4}{|l|}{ Gender $(n=276)$} \\
\hline Male & $130(53.94)$ & $377(59.37)$ & \multirow[t]{2}{*}{0.146} \\
\hline \multirow[t]{3}{*}{ Female } & $11(46.05)$ & $258(40.62)$ & \\
\hline & \multicolumn{2}{|l|}{ H. pylori infection } & \multirow[t]{2}{*}{$p$} \\
\hline & present $(n=171)$ & absent $(n=705)$ & \\
\hline Chronic atrophic gastritis $(n=205)$ & $41(23.97)$ & $164(19.28)$ & 0.726 \\
\hline Metaplasia $(n=166)$ & $46(26.9)$ & $124(17.58)$ & 0.048 \\
\hline Dysplasia $(n=48)$ & $14(8.19)$ & $34(4.82)$ & 0.232 \\
\hline Ulcerating macroscopic aspect $(n=76)$ & $23(18.7)$ & $53(7.52)$ & 0.044 \\
\hline \multicolumn{4}{|l|}{ Histological type $(n=876)$} \\
\hline Diffuse type & $76(44.44)$ & $390(55.31)$ & \multirow[t]{2}{*}{0.011} \\
\hline Intestinal type ${ }^{b}$ & $95(55.55)$ & $315(44.05)$ & \\
\hline
\end{tabular}

Values are $n(\%) .{ }^{\text {a }}$ Signet ring cell carcinoma. ${ }^{\mathrm{b}}$ Papillary + tubular + mucinous adenocarcinoma.

ronment and that of other parts of the world, suggesting distinctive various epidemiological changes. To our knowledge, in Tunisia GA is actually more common among the rural population and the most disadvantaged social classes who frequently cannot afford meat. However, the Tunisian diet is still Mediterranean type characterized by a significant consumption of vegetables and olive oil, in addition to decreased dried and salted meat consumption which was a common Tunisian custom.

Furthermore, epidemiological changes of GA in the Middle East as in the Arabic world are not clearly described in the literature. According to a Lebanese singleinstitution descriptive study, the incidence of gastric can- cer in the Lebanese population ranked seventh in males and tenth in females with an average of 240 cases per year (equivalent to 5-7 per year per 100,000 inhabitants); trends were not studied [19]. According to our present study, we confirm that both GA incidence and incidence rate have decreased in central Tunisia, starting from the year 2009. However, gastric signet ring cell carcinoma has significantly increased; its prevalence has multiplied by 2.5 (13.95\% in group A vs. $35.99 \%$ in group B; $p<0.00001$ ).

Throughout the industrialized world, GA have been "climbing" from the distal to the proximal stomach [20]. Tumors located in the distal third of the stomach have shown the most evident decrease in incidence, whereas 
proximal tumors have been stable or even increasing [21, 22 ]. The declining incidence of GA has been linked to the decreasing number of intestinal type $[1,2]$. H. pylori is the intestinal histotype's main etiological agent and a major risk factor of noncardia gastric cancer [23, 24]. It is associated with antrally (distal) restricted atrophic gastritis because intestinal metaplasia usually arise in native mucosecreting (antral) epithelia [24]. In our study HPI was significantly associated with metaplasia $(p=0.048)$ and with ulcerated macroscopic aspect $(p=0.044)$, but it had no significant association with atrophic chronic gastritis or dysplasia.

A cooperative group for the study of cancer and Helicobacter has recently published a meta-analysis of 1,228 patients with gastric cancer and 3,406 witnesses, for whom anti-HPI serology was available years prior to cancer diagnosis [25]. This meta-analysis has confirmed an increased gastric cancer risk when there was infection $(\mathrm{OR}=2.4$; 95\% CI: 2.0-2.8) [25]. When considering cancer topography, that risk was only significantly increased for the distal localization $(\mathrm{OR}=3.0 ; 95 \% \mathrm{CI}: 2.3-8)$, and not for cardia cancers $(\mathrm{OR}=1.0$; 95\% CI: 0.7-1.4) [25]. When comparing between our two groups $\mathrm{A}$ and $\mathrm{B}$, the prevalence of proximal GA increased from 19.3 to $21.12 \%$, and that of distal form lowered from 80.62 to $78.88 \%$, but those trends were not significant $(p=0.3)$. The most frequent site of GA was between the antrum and the pylorus (35.84\%; 95\% CI: $28.8-44.8 \%$ ) of our total 876 cases. However, in our series, atrophic chronic gastritis was significantly more prevalent in proximal GA compared to the distal location (19.14 vs. $9.70 \% ; p<0.00001)$.
The consequences of these epidemiological changes on our practice were a notable rise of total gastrectomy, whose rate doubled in the second period (group B) compared to the first (group $A ; p<0.00001$ ) versus lowered partial gastrectomy by the third, from $32.04 \%$ (group B) to $20.6 \%$ (group $\mathrm{A} ; p<0.00001$ ). Those consequences reflect an ever-worsening prognosis.

\section{Conclusion}

Cultural, climatic, and environmental differences between Tunisian (or North-African) and Occidental populations do not suggest that epidemiological changes in GA could be the same. However, our study has confirmed that there is a clear resemblance in those trends when the only described environmental similarity consisted of a decrease in HPI. Thus, our study confirmed that this decrease is the strongest factor at the origin of all the described epidemiological changes in GA.

\section{Acknowledgments} data.

The authors thank Dr. Leila Jaidane for her help in accessing

\section{Disclosure Statement}

All authors disclose sponsorship or funding arrangements relating to this research and disclose any possible conflicts of interest.

\section{References}

1 Bray F, Soerjomataram I: The changing global burden of cancer: transitions in human development and implications for cancer prevention and control; in Gelband $\mathrm{H}$, Jha $\mathrm{P}$, Sankaranarayanan R, Horton S (eds): Cancer: Disease Control Priorities, ed 3. Washington, International Bank for Reconstruction and Development /World Bank, 2015, vol 3, pp 23-44.

2 Laurén PA, Nevalainen TJ: Epidemiology of intestinal and diffuse types of gastric carcinoma a time-trend study in Finland with comparison between studies from high-and lowrisk areas. Cancer 1993;71:2926-2933.

-3 Kaneko S, Yoshimura T: Time trend analysis of gastric cancer incidence in Japan by histological types, 1975-1989. Br J Cancer 2001;84: 400.
4 Lambert R: Épidémiologie du cancer gastrique dans le monde. Cancéro Dig 2010;2: 31-37.

5 De Martel C, Ferlay J, Franceschi S, Vignat J, Bray F, Forman D, et al: Global burden of cancers attributable to infections in 2008: a review and synthetic analysis. Lancet Oncol 2012;13:607-615.

6 National Institute of Statistics: Tunisia statistics. Census results per governorates: Sousse, Monastir, Mahdia, Kairouan, Kasserine, Sidibouzid (online). Tunis, 2014. http://www.ins.tn/en/results-en (accessed January 24, 2017).

7 Lauren P: The two histological main types of gastric carcinoma, an attempt at a histoclinical classification. Acta Pathol Microbiol Scand 1965;64:31-49.
${ }_{8} \mathrm{Hu}$ B, El Hajj N, Sittler S, Lammert N, Barnes R, Meloni-Ehrig A: Gastric cancer: classification, histology and application of molecular pathology. J Gastrointest Oncol 2012;3:251261

9 Wilson EB: Probable inference, the law of succession, and statistical inference. J Am Stat Assoc 1927;22:209-212.

10 Pizzi M, Saraggi D, Fassan M, Megraud F, Di Mario F, Rugge M: Secondary prevention of epidemic gastric cancer in the model of Helicobacter pylori-associated gastritis. Dig Dis 2014;32:265-274.

11 Jemal A, Bray F, Center MM, Ferlay J, Ward E, Forman D: Global cancer statistics. CA Cancer J Clin 2011;61:69-90. 
12 Mansour KB, Keita A, Zribi M, Masmoudi A, Zarrouk S, Labbene M, et al: Seroprevalence of Helicobacter pylori among Tunisian blood donors (outpatients), symptomatic patients and control subjects. Gastroenterol Clin Biol 2010;34:75-82.

13 Ben Abdallah M, Zehani S, Ayoub WHB : Registre des Cancers Nord-Tunisie. Tunis, Ministre de la Sante Publique, Institut Salah Azaiez, Institut National de la Sante Publique, 2009.

14 Holcombe C: Helicobacter pylori: the African enigma. Gut 1992;33:429-431.

15 Bouali R, Moussa MB, Jemaa A, Tounsi C, Hila A, Barguelil F, et al: High prevalence of Helicobacter pylori (HP) infection in Tunisia. Am J Gastroenterol 2003;98:S40.

16 Wu C-Y, Lin J-T: The changing epidemiology of Asian digestive cancers: from etiologies and incidences to preventive strategies. Best Pract Res Clin Gastroenterol 2015;29:843853.
17 Lee YC, Lin JT: Screening and treating Helicobacter pylori infection for gastric cancer prevention on the population level. J Gastroenterol Hepatol 2017;32:1160-1169.

18 Ghrissi R, amine Elghali M, Ghammam R, Gouader A, Hamila F, Letaief MR: The changing trends in epidemiological characteristics of gastric adenocarcinoma: a Tunisian center experience. Int Surg J 2016;3:18-22.

19 Assi T, El Rassy E, Khazzaka A, Moussa T, Ibrahim T, Kattan C, et al: Characteristics of gastric cancer in Lebanon: a descriptive study from a single institutional experience. J Gastrointest Cancer 2018;49:21-24.

20 Brown LM, Devesa SS: Epidemiologic trends in esophageal and gastric cancer in the United States. Surg Oncol Clin North Am 2002;11: 235-256.
21 Wu H, Rusiecki JA, Zhu K, Potter J, Devesa SS: Stomach carcinoma incidence patterns in the United States by histologic type and anatomic site. Cancer Epidemiol Biomarkers Prev 2009;18:1945-1952.

22 Verdecchia A, Corazziari I, Gatta G, Lisi D, Faivre J, Forman D: Explaining gastric cancer survival differences among European countries. Int J Cancer 2004;109:737-741.

23 Ang TL, Fock KM: Clinical epidemiology of gastric cancer. Singapore Med J 2014;55:621.

24 Rugge M, Capelle LG, Fassan M: Individual risk stratification of gastric cancer: evolving concepts and their impact on clinical practice. Best Pract Res Clin Gastroenterol 2014;28: 1043-1053.

25 Helicobacter and Cancer Collaborative Group: Gastric cancer and Helicobacter pylori: a combined analysis of 12 case control studies nested within prospective cohorts. Gut 2001;49:347-353. 